\title{
Isotherms for the sorption of zinc and copper onto kaolinite: comparison of various error functions
}

\author{
Sh. Shahmohammadi-Kalalagh $\cdot$ H. Babazadeh
}

Received: 7 October 2012/Revised: 11 February 2013/Accepted: 12 March 2013/Published online: 24 April 2013

(C) Islamic Azad University (IAU) 2013

\begin{abstract}
In this research, the equilibrium sorption of $\mathrm{Zn}$ (II) and $\mathrm{Cu}$ (II) by kaolinite was explained using the Freundlich, Langmuir and Redlich-Peterson isotherms, via both linear and non-linear regression analyses. In the case of non-linear regression method, the best-fitting model was evaluated using six different error functions, namely coefficient of determination $\left(r^{2}\right)$, hybrid fractional error function (HYBRID), Marquardt's percent standard deviation (MPSD), average relative error (ARE), sum of the errors squared (SSE) and sum of the absolute errors (EABS). The examination of error estimation methods showed that the Langmuir model provides the best fit for the experimental equilibrium data for both linear and nonlinear regression analyses. The SSE function was found to be a better option to minimize the error distribution between the experimental equilibrium data and predicted two-parameter isotherms. In the case of three-parameter isotherm, HYBRID was found to be the best error function to minimize the error distribution structure between experimental equilibrium data and theoretical isotherms. Non-linear method was found to be more appropriate method for estimating the isotherm parameters.
\end{abstract}

Keywords Adsorption · Freundlich · Langmuir · Redlich-Peterson $\cdot$ Regression analysis

Sh. Shahmohammadi-Kalalagh $(\bowtie)$

Department of Water Sciences and Engineering,

East Azarbaijan Science and Research Branch,

Islamic Azad University, Tabriz, Iran

e-mail: shahmohammadi_sh@hotmail.com

H. Babazadeh

Department of Water Sciences and Engineering, Science and

Research Branch, Islamic Azad University, Tehran, Iran

\section{Introduction}

Heavy metals in the environment are a source of some concern because of their potential reactivity, toxicity, and mobility in the soil. In order to solve the problems of heavy metal pollution in the environment, it is important to bring pragmatic solutions to the issue. There are several methods for treatment of metal-contaminated effluents such as chemical precipitation (Jüttner et al. 2000; Bose et al. 2002; Wingenfelder et al. 2005), coagulation-flocculation (Ayoub et al. 2001; Semerjian and Ayoub 2003), ultrafiltration (Eckenfelder 2000), flotation (Jokela and Keskitalo 1999; Matis et al. 2003), ion exchange (Eckenfelder 2000) and adsorption (Abdel-Ghani et al. 2009; Tashauoei et al. 2010; Zavvar Mousavi and Seyedi 2011). They have their inherent advantages and limitations in application. Among the numerous treatment technologies developed for the removal of pollutant from the aqueous environment, adsorption is receiving increasing attention in becoming an attractive and promising technology because of its simplicity, cheaper pollution control method, ease of operation and handling (Bhattacharya et al. 2006; Kunda and Gupta 2006; Shahmohammadi-Kalalagh et al. 2011). Clay minerals are copious in nature, cost less, have a high specific surface area and exchange capacity and hence are strong candidates as adsorbents for the removal of heavy metals from wastewaters.

Equilibrium relationships between adsorbent and adsorbate are described by adsorption isotherms. Search for the best-fit adsorption isotherm using the method of least squares is the most widely used technique by several researchers (Kumar and Sivanesan 2007; Kumar et al. 2008) to predict the optimum isotherm. As an alternative to the linear transformation, non-linear optimization has also been applied by various researchers (Malek and Farooq 
1996; Porter et al. 1999; Ho et al. 2002; Allen et al. 2003; $\mathrm{Ng}$ et al. 2003; Ho 2004) to determine isotherm parameter values which require an error function assessment, in order to evaluate the fit of the isotherm to the experimental results for the removal of variety of components from the aqueous environment. Several error deviation functions have been used to predict the optimum isotherm, such as the coefficient of determination $\left(r^{2}\right)$, hybrid fractional error function (HYBRID), Marquardt's percent standard deviation (MPSD), the average relative error (ARE), sum of the errors squared (SSE) and sum of the absolute errors (EABS) (Porter et al. 1999; Ho et al. 2002; $\mathrm{Ng}$ et al. 2002; Allen et al. 2003; Wong et al. 2004). However, no detailed studies were available so far comparing the accuracy of these error functions in predicting the isotherm parameters and also the optimum isotherm.

In the present study, a comparison of six different error functions in minimizing the error distribution between the experimental and predicted isotherms is discussed using the experimental data of $\mathrm{Zn}$ (II) and $\mathrm{Cu}$ (II) onto kaolinite. The three widely used Freundlich, Langmuir and RedlichPeterson isotherms were used to discuss this issue. The method of least squares was used to predict the isotherm by linear regression method. A trial and error method was used for nonlinear regression to minimize or maximize the objective function using the solver add-in function, Microsoft Excel, Microsoft. This study was conducted in Islamic Azad University, Science and Research Branch, Tehran, Iran in Autumn 2011.

\section{Materials and methods}

The materials used in this study are kaolinite (from the Iran china clay industries Co.) and chemical materials such as solutions and reagents. Kaolinite was used as the adsorbent. The chemical composition and some physical properties of kaolinite are presented in Table 1. The molecular structure of kaolinite is sketched in Fig. 1 (Vimonses et al. 2009). Its structural formula is $\mathrm{Al}_{2} \mathrm{Si}_{2} \mathrm{O}_{5} \mathrm{OH}_{4}$. The elements contained in pure kaolinite are arranged to form one silica sheet and one alumina sheet (Sposito 1989). Solutions of selected heavy metals (copper and zinc) were used as the adsorbate for batch adsorption experiments. With reference to the soil profile and groundwater contamination, a low $\mathrm{pH}$ for solution was chosen. Accordingly, hydrochloric acid was used to adjust the $\mathrm{pH}$ of each solution to 4.5.

Suspensions were prepared on dry solid basis into a uniform powdery texture and mixed with various concentrations of metal solutions. The initial concentrations of $\mathrm{Cu}$ and $\mathrm{Zn}$ solutions were selected as 50, 200, 500, 1,000, and $2,000 \mathrm{mg} / \mathrm{L}$. These metal concentrations were selected to cover a wide range most commonly found in sewage
Table 1 The chemical composition and some physical properties of kaolinite used in the present study

\begin{tabular}{ll}
\hline Constituents & Quantity (\%) \\
\hline $\mathrm{Al}_{2} \mathrm{O}_{3}$ & 38.60 \\
$\mathrm{SiO}_{2}$ & 45.71 \\
$\mathrm{Fe}_{2} \mathrm{O}_{3}$ & 0.38 \\
$\mathrm{TiO}_{2}$ & 1.15 \\
$\mathrm{CaO}$ & 0.10 \\
$\mathrm{MgO}$ & 0.34 \\
$\mathrm{Na}_{2} \mathrm{O}$ & 0.31 \\
$\mathrm{~K}_{2} \mathrm{O}$ & 0.10 \\
Loss on ignition & 13.31 \\
$\mathrm{Cation}$ exchange capacity & $8 \mathrm{meq} / 100 \mathrm{~g}$ \\
Mean particle size & $59 \times 10^{-4} \mathrm{~cm}$ \\
Surface area & $12.76 \mathrm{~m}^{2} / \mathrm{g}$ \\
Porosity & 0.42 \\
Density & $1.49 \mathrm{~g} / \mathrm{cm}^{3}$ \\
\hline
\end{tabular}

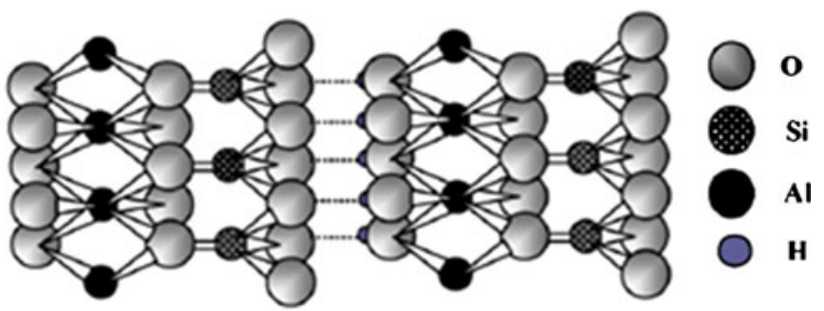

Fig. 1 Molecular structure of kaolinite (Vimonses et al. 2009)

sludge, some industrial wastes, and municipal solid wastes. The solutions of heavy metals were applied to the kaolinite at 1:10 (solid:solution ratio) (Yong et al. 1992), i.e., $40 \mathrm{~g}$ of dry kaolinite and $400 \mathrm{~mL}$ of solutions. The mixed solutions are mounted on the stirrer plate during experimental period, to prevent any possible sedimentation and to provide proper agitation. Following agitation, $15 \mathrm{~mL}$ aliquots were removed to determine metal concentrations. Aliquots were then centrifuged at $6,000 \mathrm{rpm}$ for $10 \mathrm{~min}$ in plastic Nalgene centrifuge tubes equipped with screw-on caps.

At the end of centrifugation, the supernatant is filtered and stored in $10 \mathrm{ml}$ glass vials prior to atomic absorption (AA) spectroscopy. The total metal content in the filtered solutions was determined by AA spectroscopy in accordance with standard procedures. The total initial metal concentration minus the metal concentration in the supernatant was taken as the metal adsorbed by kaolinite. Experiments were conducted (without replication) at room temperature $\left(20 \pm 1{ }^{\circ} \mathrm{C}\right)$, over a range of metal concentrations, keeping the initial $\mathrm{pH}$ constant [The kaolinite under consideration (hydrated poorly crystalline (PX)), is relatively chemically inert and reacts with acids and bases only under extreme conditions. Also, it is water processed, 
which reduces soluble salt contents to extremely low level (Sposito 1989). On the other hand, the adjusted $\mathrm{pH}$ is near the point of zero charge (PZC) value of kaolinite and it seems that no considerable change in $\mathrm{pH}$ during the experiment may be found].

Data evaluation

The amount of $\mathrm{Zn}(\mathrm{II})$ and $\mathrm{Cu}$ (II) adsorbed by the kaolinite was determined using a mass balance equation expressed as in Eq. (1):

$q_{\mathrm{e}}=\frac{V\left(C_{0}-C_{\mathrm{e}}\right)}{m}$

where $q_{\mathrm{e}}$ is metal concentration on the kaolinite $(\mathrm{mg} / \mathrm{g})$ at equilibrium, $C_{\mathrm{e}}$ is metal concentration in solution $(\mathrm{mg} / \mathrm{L})$ at equilibrium, $C_{0}$ is initial metal concentration in solution $(\mathrm{mg} / \mathrm{L}), V$ is volume of initial metal solution used (L), and $m$ is mass of kaolinite used $(\mathrm{g})$.

\section{Results and discussion}

\section{Linear regression analysis}

The linear least-squares method to the linearly transformed isotherm equations was widely applied to confirm the experimental data and isotherms using coefficient of determination (Ho et al. 2005; Kumar and Sivanesan 2006). The widely used linearized form of Freundlich, Langmuir, and Redlich-Peterson isotherms which are found to be the best-fit expressions in representing most of the experimental equilibrium data is shown in Table 2. The Freundlich, Langmuir, and Redlich-Peterson constants can be obtained from the slope and intercept of plot between $\ln \left(q_{\mathrm{e}}\right)$ versus $\ln \left(C_{\mathrm{e}}\right), C_{\mathrm{e}} / q_{\mathrm{e}}$ versus $C_{\mathrm{e}}$ and $\ln \left(A C_{\mathrm{e}} / q_{\mathrm{e}}-1\right)$ versus $\ln \left(C_{\mathrm{e}}\right)$, respectively. In the case of Redlich-Peterson isotherm, the constants were obtained by maximizing the $r^{2}$ value using a trial and error procedure using the solver addin with Microsoft's spreadsheet, Microsoft excel. The way of obtaining the isotherm constants was explained in Table 2.

Figures 2 and 3 show the experimental equilibrium data and the predicted theoretical isotherms using linear method for the sorption of $\mathrm{Zn}(\mathrm{II})$ and $\mathrm{Cu}(\mathrm{II})$ onto kaolinite,

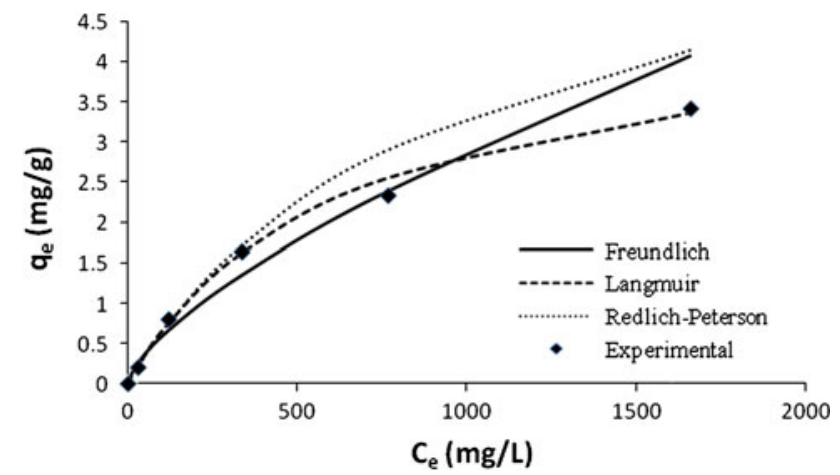

Fig. 2 Adsorption isotherms for $\mathrm{Zn}(\mathrm{II})$ onto kaolinite by linear method

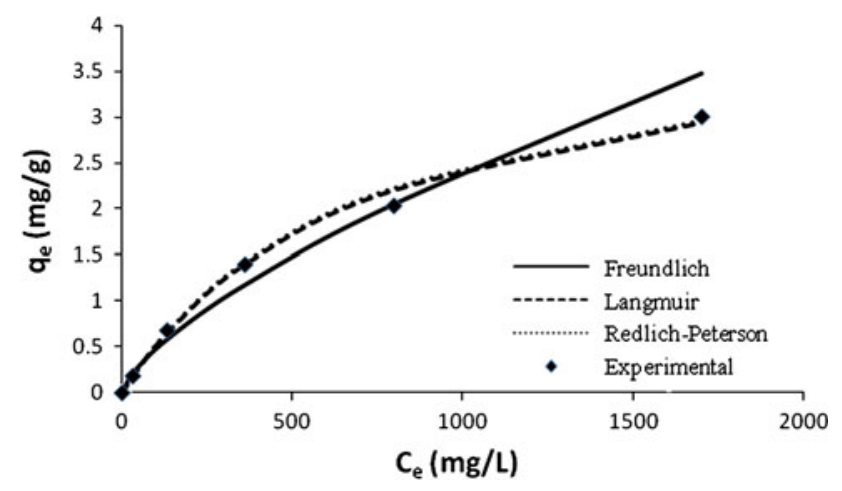

Fig. 3 Adsorption isotherms for $\mathrm{Cu}(\mathrm{II})$ onto kaolinite by linear method

Table 3 Isotherm constants for $\mathrm{Zn}(\mathrm{II})$ and $\mathrm{Cu}(\mathrm{II})$ onto kaolinite by linear method

\begin{tabular}{lll}
\hline & $\mathrm{Zn}(\mathrm{II})$ & $\mathrm{Cu}(\mathrm{II})$ \\
\hline Freundlich & & \\
$K_{\mathrm{F}}(\mathrm{mg} / \mathrm{g})(\mathrm{L} / \mathrm{g})^{n}$ & 0.0236 & 0.0194 \\
$1 / n$ & 0.6944 & 0.6976 \\
$r^{2}$ & 0.9700 & 0.9780 \\
Langmuir & & \\
$K_{\mathrm{L}}(\mathrm{L} / \mathrm{mg})$ & 0.0016 & 0.0014 \\
$q_{\mathrm{m}}(\mathrm{mg} / \mathrm{g})$ & 4.6250 & 4.1649 \\
$r^{2}$ & 0.9942 & 0.9945 \\
Redlich-Peterson & & \\
$A(\mathrm{~L} / \mathrm{g})$ & 0.0071 & 0.0060 \\
$B\left(\mathrm{~L} / \mathrm{mg}{ }^{1-1 / A}\right)$ & 0.0015 & 0.0015 \\
$G$ & 0.9595 & 0.9944 \\
$r^{2}$ & 0.9927 & 0.9934 \\
\hline
\end{tabular}

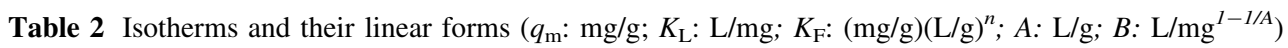

\begin{tabular}{llll}
\hline Isotherm & Non-linear form & Linear form & Plot \\
\hline Freundlich & $q_{e}=K_{\mathrm{F}} C_{\mathrm{e}}^{1 / n}$ & $\ln \left(q_{\mathrm{e}}\right)=\ln \left(K_{\mathrm{F}}\right)+\frac{1}{n} \ln \left(C_{\mathrm{e}}\right)$ & $\ln \left(q_{\mathrm{e}}\right)$ vs. $\ln \left(C_{\mathrm{e}}\right)$ \\
Langmuir & $q_{\mathrm{e}}=\frac{K_{\mathrm{L}} C_{\mathrm{e}}}{1+K_{\mathrm{e}} C_{\mathrm{e}}}$ & $\frac{C_{\mathrm{e}}}{q_{\mathrm{e}}}=\frac{1}{\mathrm{~K}_{\mathrm{L}} q_{\mathrm{m}}}+\frac{1}{q_{\mathrm{m}}} C_{\mathrm{e}}$ & $\frac{C_{\mathrm{e}}}{q_{\mathrm{e}}} \mathrm{vs} \cdot C_{\mathrm{e}}$ \\
Redlich-Peterson & $q_{\mathrm{e}}=\frac{A C_{\mathrm{e}}}{1+B C_{\mathrm{e}}^{\mathrm{e}}}$ & $\ln \left(A \frac{C_{\mathrm{e}}}{q_{\mathrm{e}}}-1\right)=\ln (B)+g \ln \left(C_{\mathrm{e}}\right)$ & $\ln \left(A \frac{C_{\mathrm{e}}}{q_{\mathrm{e}}}-1\right)$ vs. $\left(C_{\mathrm{e}}\right)$ \\
\hline
\end{tabular}


respectively. The predicted isotherm constants for the $\mathrm{Zn}(\mathrm{II})$ and $\mathrm{Cu}(\mathrm{II})$ and their corresponding $r^{2}$ values by the linear method were shown in Table 3. From Table 3, the relatively lower $r^{2}$ values for Freundlich isotherm when compared to Langmuir and Redlich-Peterson isotherm suggest that it may not be appropriate to use this model in representing the equilibrium uptake of $\mathrm{Zn}$ (II) and $\mathrm{Cu}$ (II) by kaolinite. From Table 3, it can be observed that RedlichPeterson and Langmuir isotherms very well represent the experimental equilibrium data with a higher $r^{2}$ value $(>0.99)$.

Figure 3 shows that the Redlich-Peterson and Langmuir isotherms overlapped each other, and seemed to be the best-fitting models for the experiment results with the same values of coefficient of determination (Table 3). Thus, Langmuir isotherm is a special case of Redlich-Peterson isotherm when constant $g$ was unity $(g \approx 1)$. The similar findings have been reported by other researchers as well (Kumar and Sivanesan 2007; Subramanyam and Das 2009).

Previously, several research reports suggested non-linear method as a better way to obtain the isotherm parameters as sometime linearization of non-linear experimental data may distort the error distribution structure of isotherm (Ho 2004; Kumar 2006). Based on any of the error measures, better fits can be obtained for any isotherm using non-linear isotherm. Thus, in the present study, nonlinear regression method was used to determine the optimum isotherm out of the three widely used isotherms (Freundlich, Langmuir, and Redlich-Peterson) studied.

Non-linear method

Due to the inherent bias resulting from linearization, nonlinear regression was applied to determine alternative isotherm parameter sets. In the case of non-linear method, previous research studies reported that the predicted isotherms were found to be varying with the error function used while minimizing the error distribution between the experimental and predicted isotherms (Porter et al. 1999; Ho et al. 2002; Ng et al. 2002; Allen et al. 2003; Wong et al. 2004). Thus, in order to analyze the impact of various error functions on the predicted isotherms, six error functions $r^{2}$, HYBRID, MPSD, ARE, SSE and EABS were

Table 4 Different error functions used for equilibrium isotherm analyses

\begin{tabular}{|c|c|c|c|}
\hline Error function & Abbreviation & Definition/expression & Reference \\
\hline The coefficient of determination & $r^{2}$ & $\frac{\sum_{i=1}^{n}\left(q_{\mathrm{e}, \text { calc }}-\bar{q}_{\mathrm{e}, \mathrm{exp}}\right)_{i}^{2}}{\sum_{i=1}^{n}\left(q_{\mathrm{e}, \text { calc }}-\bar{q}_{\mathrm{e}, \mathrm{exp}}\right)_{i}^{2}+\sum_{i=1}^{n}\left(q_{\mathrm{e}, \text { aalc }}-q_{\mathrm{e}, \mathrm{exp}}\right)_{i}^{2}}$ & Ho (2004) \\
\hline The hybrid fractional error function & HYBRID & $\frac{100}{n-p} \sum_{i=1}^{n}\left[\frac{\left(q_{\mathrm{e}, \mathrm{exp}}-q_{\mathrm{e}, \text { aal }}\right)^{2}}{q_{\mathrm{e}, \mathrm{xp}}}\right]_{i}$ & Allen et al. (2003) \\
\hline Marquardt's percent standard deviation & MPSD & $100 \sqrt{\frac{1}{n-p} \sum_{i=1}^{n}\left(\frac{q_{\mathrm{e}, \mathrm{exp}}-q_{\mathrm{e}, \mathrm{calc}}}{q_{\mathrm{e}, \mathrm{exp}}}\right)_{i}^{2}}$ & Allen et al. (2003) \\
\hline The average relative error & ARE & $\frac{100}{n} \sum_{i=1}^{n}\left|\frac{q_{\mathrm{e}, \exp }-q_{\mathrm{e}, \mathrm{alc}}}{q_{\mathrm{e}, \mathrm{exp}}}\right|_{i}$ & Allen et al. (2003) \\
\hline The sum of the errors squared & SSE & $\sum_{i=1}^{n}\left(q_{\mathrm{e}, \mathrm{calc}}-q_{\mathrm{e}, \exp }\right)_{i}^{2}$ & $\mathrm{Ng}$ et al. (2002) \\
\hline The sum of the absolute errors & EABS & $\sum_{i=1}^{n}\left|q_{\mathrm{e}, \mathrm{calc}}-q_{\mathrm{e}, \exp }\right|_{i}$ & $\mathrm{Ng}$ et al. (2002) \\
\hline
\end{tabular}

$n$ is the number of experimental data points, $p$ is the number of parameters in each isotherm model, $q_{\mathrm{e}, \mathrm{cal}}(\mathrm{mg} / \mathrm{g})$ is the theoretically calculated adsorption capacity at equilibrium and $q_{\mathrm{e}, \text { exp }}(\mathrm{mg} / \mathrm{g})$ is the experimental adsorption capacity at equilibrium

Table 5 Isotherm error deviation data related to the sorption of $\mathrm{Zn}(\mathrm{II})$ and $\mathrm{Cu}(\mathrm{II})$ onto kaolinite using six commonly used functions

\begin{tabular}{|c|c|c|c|c|c|c|c|c|c|c|c|c|}
\hline \multirow[t]{2}{*}{ Error functions } & \multicolumn{2}{|l|}{$r^{2}$} & \multicolumn{2}{|l|}{ ARE } & \multicolumn{2}{|l|}{ MSPD } & \multicolumn{2}{|c|}{ HYBRID } & \multicolumn{2}{|l|}{ EABS } & \multicolumn{2}{|l|}{ SSE } \\
\hline & $\mathrm{Zn}(\mathrm{II})$ & $\mathrm{Cu}(\mathrm{II})$ & $\mathrm{Zn}(\mathrm{II})$ & $\mathrm{Cu}(\mathrm{II})$ & $\mathrm{Zn}(\mathrm{II})$ & $\mathrm{Cu}(\mathrm{II})$ & $\mathrm{Zn}(\mathrm{II})$ & $\mathrm{Cu}(\mathrm{II})$ & $\mathrm{Zn}(\mathrm{II})$ & $\mathrm{Cu}(\mathrm{II})$ & $\mathrm{Zn}(\mathrm{II})$ & $\mathrm{Cu}(\mathrm{II})$ \\
\hline \multicolumn{13}{|l|}{ Linear form } \\
\hline Freundlich & 0.9700 & 0.9780 & 16.0501 & 12.7778 & 22.7330 & 18.2112 & 7.1882 & 4.3217 & 1.1855 & 0.8449 & 0.5377 & 0.2873 \\
\hline Langmuir & 0.9942 & 0.9945 & 4.5388 & 3.2230 & 7.1530 & 6.0292 & 0.8502 & 0.5608 & 0.3498 & 0.2730 & 0.0537 & 0.0332 \\
\hline Redlich-Peterson & 0.9927 & 0.9934 & 11.5951 & 3.2487 & 23.7515 & 7.1405 & 15.1690 & 0.9773 & 1.4314 & 0.2730 & 0.8685 & 0.0394 \\
\hline \multicolumn{13}{|l|}{ Non-linear form } \\
\hline Freundlich & 0.9790 & 0.9877 & 17.1684 & 14.6649 & 26.7441 & 26.4800 & 5.2506 & 2.8057 & 0.8369 & 0.5192 & 0.2155 & 0.0822 \\
\hline Langmuir & 0.9930 & 0.9945 & 5.2232 & 5.5862 & 8.1126 & 8.0508 & 0.8870 & 0.5955 & 0.4069 & 0.3075 & 0.0471 & 0.0286 \\
\hline Redlich-Peterson & 0.9930 & 0.9945 & 5.2740 & 7.0924 & 9.9817 & 12.1690 & 1.3347 & 1.1769 & 0.4100 & 0.3885 & 0.0472 & 0.0375 \\
\hline
\end{tabular}



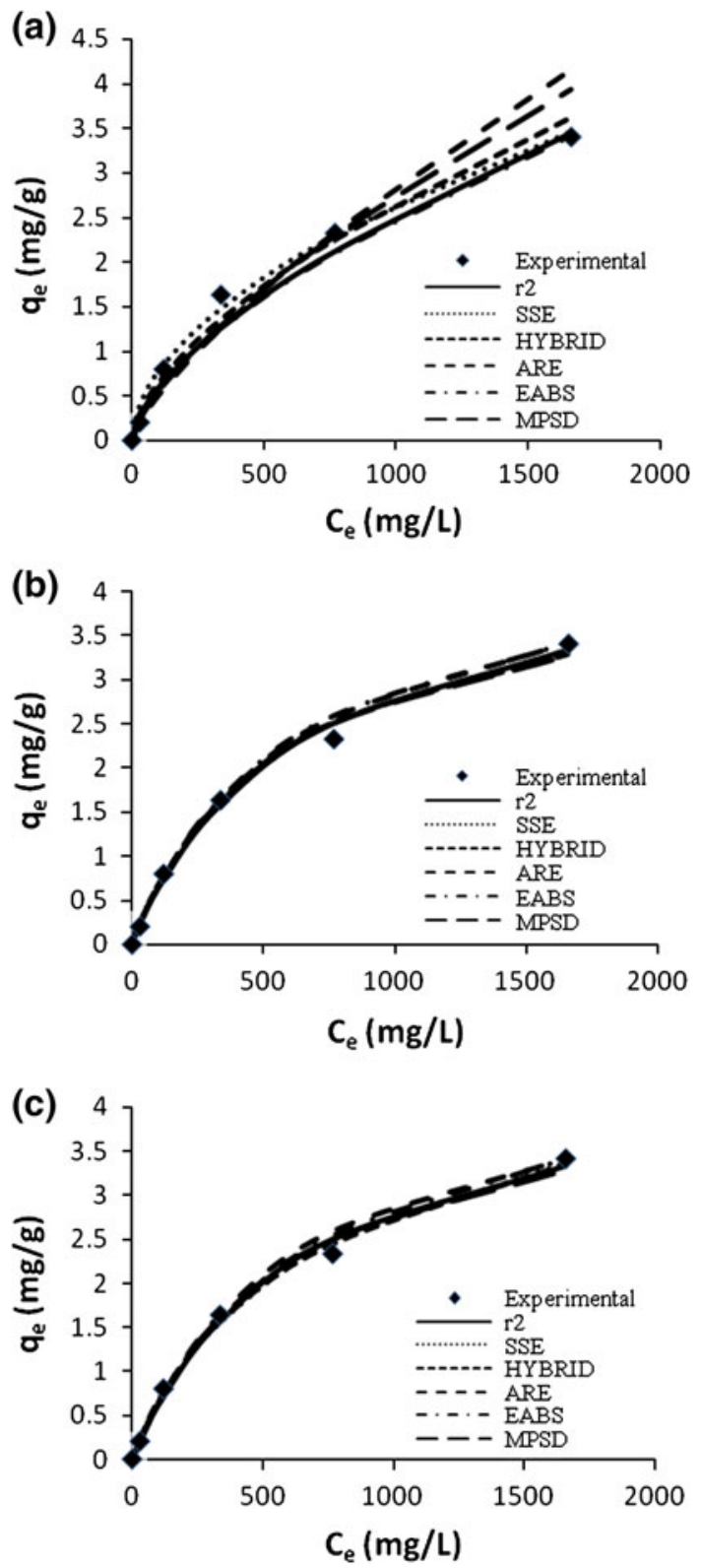

Fig. 4 Isotherm plots for $\mathrm{Zn}$ (II) onto kaolinite using various error analysis methods: a Freundlich isotherm, b Langmuir isotherm and, c Redlich-Peterson isotherm

examined and in each case, the isotherm parameters were determined by minimizing the respective error function across the concentration range studied, using the solver add-in for Microsoft Excel. The explanations of various error functions used in the present study are given in Table 4.

By comparing the results of the values of the error functions (Table 5), it is found that the Langmuir model is the most suitable model to satisfactorily describe the studied sorption phenomenon. Indeed, the highest $r^{2}$ value and the lowest ARE, MSPD, HYBRID, EABS, and SSE
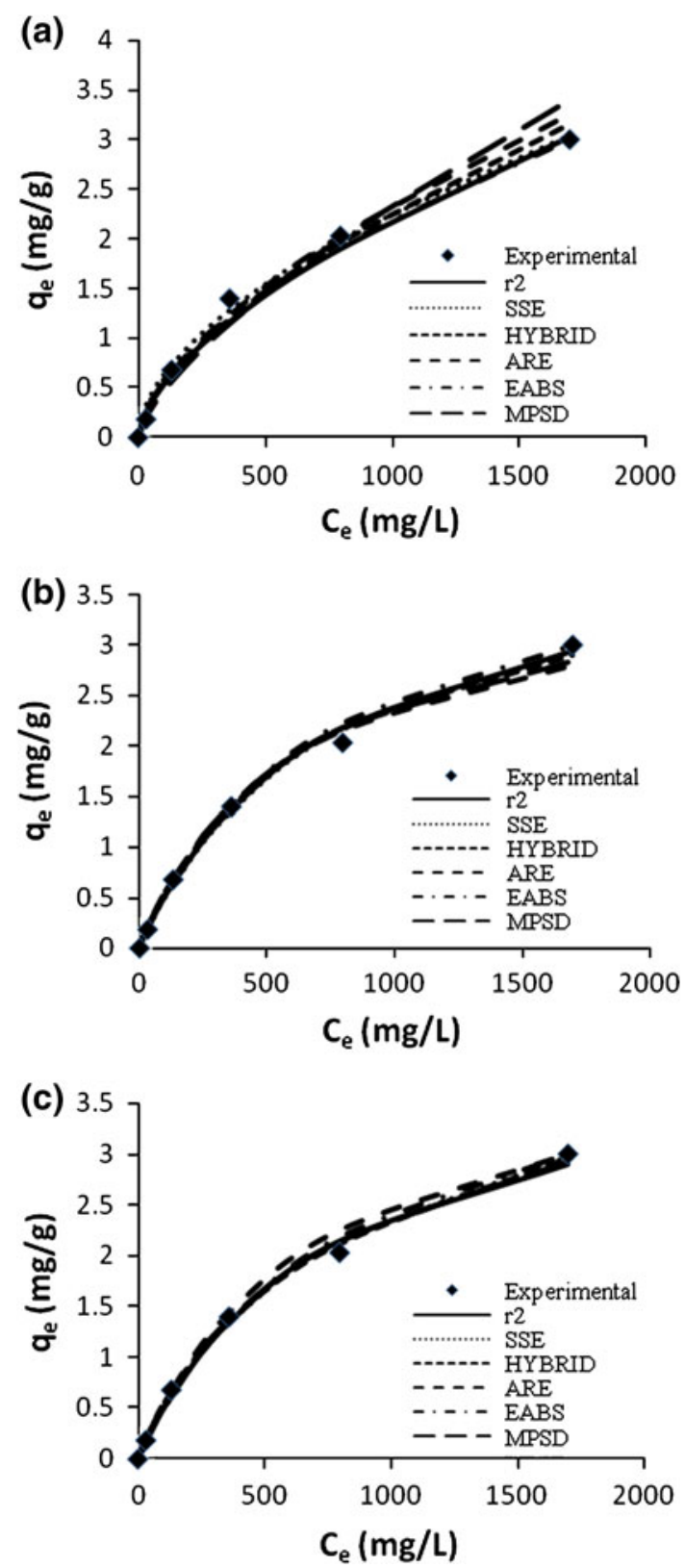

Fig. 5 Isotherm plots for $\mathrm{Cu}(\mathrm{II})$ onto kaolinite using various error analysis methods: a Freundlich isotherm, b Langmuir isotherm and c Redlich-Peterson isotherm

values were found when modelling the equilibrium data using the Langmuir, for both linear and non-linear regression analyses (cf. Table 5).

Figure $4 \mathrm{a}-\mathrm{c}$ shows the experimental and predicted Freundlich, Langmuir, and Redlich-Peterson isotherms for $\mathrm{Zn}$ (II) onto kaolinite by minimizing the error distribution between the experimental and the theoretical isotherms using various error functions explained in Table 4. From Fig. 4a-c, it is observed that the predicted theoretical isotherm was found to be varying with respect to the error functions used. A similar observation was found 
Table 6 Predicted isotherm by minimizing the error distribution using five different error functions for $\mathrm{Zn}(\mathrm{II})$ adsorption onto kaolinite

\begin{tabular}{|c|c|c|c|c|c|c|}
\hline $\begin{array}{l}\text { Error } \\
\text { functions }\end{array}$ & $r^{2}$ & SSE & HYBRID & ARE & EABS & MPSD \\
\hline \multicolumn{7}{|c|}{ Freundlich } \\
\hline$K_{\mathrm{F}}$ & 0.0321 & 0.0657 & 0.0377 & 0.0158 & 0.0321 & 0.0217 \\
\hline $1 / n$ & 0.6305 & 0.5348 & 0.6157 & 0.7515 & 0.6292 & 0.7012 \\
\hline $\mathrm{OF}^{\mathrm{a}}$ & 0.9790 & 0.0730 & 4.1212 & 14.6520 & 0.8343 & 21.9003 \\
\hline \multicolumn{7}{|l|}{ Langmuir } \\
\hline$K_{\mathrm{L}}$ & 0.0015 & 0.0015 & 0.0017 & 0.0015 & 0.0016 & 0.0017 \\
\hline$q_{\mathrm{m}}$ & 4.6710 & 4.6723 & 4.4700 & 4.7584 & 4.7081 & 4.4516 \\
\hline $\mathrm{OF}^{\mathrm{a}}$ & 0.9930 & 0.0471 & 0.7695 & 4.3092 & 0.3098 & 6.8767 \\
\hline \multicolumn{7}{|c|}{ Redlich-Peterson } \\
\hline$A$ & 0.0070 & 0.0082 & 0.0085 & 0.0073 & 0.0070 & 0.0075 \\
\hline$B$ & 0.0015 & 0.0054 & 0.0058 & 0.0014 & 0.0015 & 0.0018 \\
\hline$g$ & 1.0000 & 0.8557 & 0.8522 & 1.0152 & 0.9957 & 0.9876 \\
\hline $\mathrm{OF}^{\mathrm{a}}$ & 0.9930 & 0.0256 & 0.5144 & 4.2233 & 0.3520 & 6.8683 \\
\hline
\end{tabular}

a Objective function for the minimum error distribution between experimental and predicted isotherms

Table 7 Predicted isotherm by minimizing the error distribution using five different error functions for $\mathrm{Cu}(\mathrm{II})$ adsorption onto kaolinite

\begin{tabular}{|c|c|c|c|c|c|c|}
\hline $\begin{array}{l}\text { Error } \\
\text { functions }\end{array}$ & $r^{2}$ & SSE & HYBRID & ARE & EABS & MPSD \\
\hline \multicolumn{7}{|l|}{ Freundlich } \\
\hline$K_{\mathrm{F}}$ & 0.0311 & 0.0479 & 0.0297 & 0.0312 & 0.0393 & 0.0185 \\
\hline $1 / n$ & 0.6152 & 0.5581 & 0.6277 & 0.6251 & 0.5829 & 0.7009 \\
\hline $\mathrm{OF}^{\mathrm{a}}$ & 0.9877 & 0.0406 & 2.4697 & 13.9834 & 0.3976 & 17.8239 \\
\hline \multicolumn{7}{|l|}{ Langmuir } \\
\hline$K_{\mathrm{L}}$ & 0.0013 & 0.0012 & 0.0014 & 0.0016 & 0.0013 & 0.0015 \\
\hline$q_{\mathrm{m}}$ & 4.2721 & 4.3305 & 4.0920 & 3.8166 & 4.3367 & 3.9100 \\
\hline $\mathrm{OF}^{\mathrm{a}}$ & 0.9945 & 0.0279 & 0.5325 & 2.8802 & 0.2402 & 5.0934 \\
\hline \multicolumn{7}{|c|}{ Redlich-Peterson } \\
\hline$A$ & 0.0054 & 0.0063 & 0.0069 & 0.0061 & 0.0054 & 0.0064 \\
\hline$B$ & 0.0013 & 0.0047 & 0.0066 & 0.0015 & 0.0013 & 0.0038 \\
\hline$g$ & 1.0000 & 0.8509 & 0.8189 & 0.9912 & 0.9912 & 0.8852 \\
\hline $\mathrm{OF}^{\mathrm{a}}$ & 0.9945 & 0.0141 & 0.2250 & 2.9557 & 0.2868 & 4.1140 \\
\hline
\end{tabular}

a Objective function for the minimum error distribution between experimental and predicted isotherms for $\mathrm{Cu}$ (II) onto kaolinite (Fig. 5a-c). The variation in the predicted isotherms was found to be more pronounced for Langmuir and Redlich-Peterson isotherms (Figs. 4b, c; $5 b, c)$.

The calculated isotherm parameters and the corresponding error functions for the minimum error distribution between the experimental equilibrium data and predicted isotherm for $\mathrm{Zn}$ (II) and $\mathrm{Cu}(\mathrm{II})$ are given in Tables 6 and 7, respectively. From Tables 6 and 7, other than $r^{2}$, all the other error functions studied corresponding to the minimized deviations between the experimental equilibrium data and predicted isotherms. In the case of $r^{2}$, the RedlichPeterson isotherm was found to be the best-fit isotherm followed by Langmuir isotherm.

Figure $6 \mathrm{a}, \mathrm{b}$ shows the experimental equilibrium data and predicted isotherms for the sorption of $\mathrm{Zn}$ (II) onto kaolinite by maximizing $r^{2}$ function and minimizing the MPSD error function, respectively. From Fig. 6a, b, it can be observed that Redlich-Peterson isotherm exactly overlaps the Langmuir isotherm. Thus, Langmuir isotherm is a special case of Redlich-Peterson isotherm when constant $g$ was unity. A similar observation was observed for the sorption of $\mathrm{Cu}$ (II) onto kaolinite (Fig. 7a, b). A similar trend was observed for the predicted isotherms by minimizing the error functions HYBRID, ARE, EABS, and SSE for both $\mathrm{Zn}(\mathrm{II})$ and $\mathrm{Cu}(\mathrm{II})$ (not shown).

In order to check which error function minimizes the error distribution between the experimental and theoretical isotherms, another statistical-term coefficient of nondetermination, $K^{2}$, was used (Kumar et al. 2008). The coefficient of non-determination, $K^{2}$, was defined as:

$$
\begin{aligned}
K^{2}= & \frac{\text { Unexplained variance }}{\text { Total variance }}=1-\frac{\text { Explained variance }}{\text { Total variance }} \\
& =1-r^{2}
\end{aligned}
$$

The coefficient of non-determination is a much more useful measure of the linear or non-linear co-variation of two variables. The $K^{2}$ will be very much useful to derive any conclusion about the extent of the relationship between
Fig. 6 a Isotherms by maximizing $r^{2}$ function for $\mathrm{Zn}$ (II) onto kaolinite. b Isotherms by minimizing MPSD function for $\mathrm{Zn}$ (II) onto kaolinite
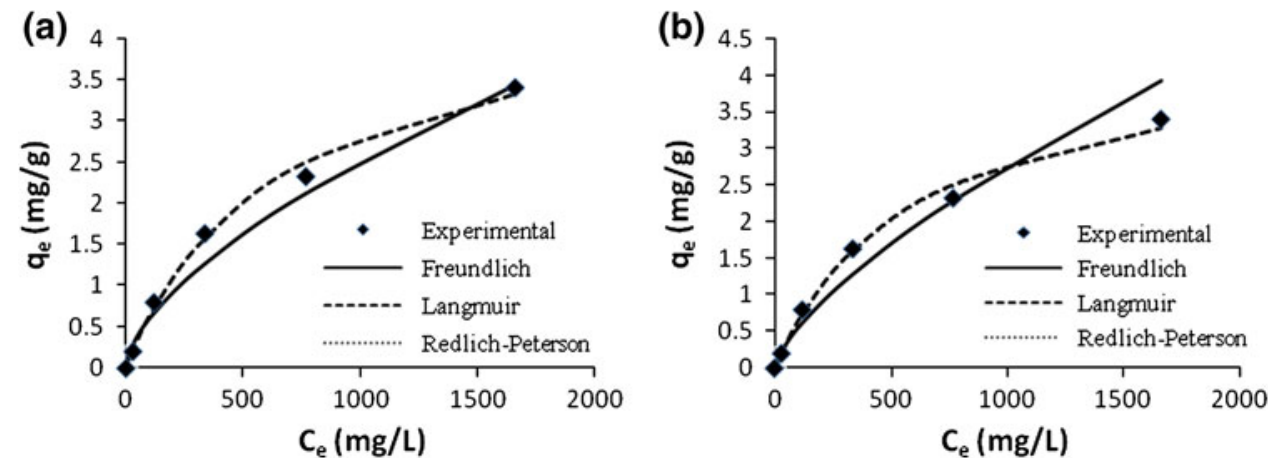
Fig. 7 a Isotherms by maximizing $r^{2}$ function for $\mathrm{Cu}(\mathrm{II})$ onto kaolinite. b Isotherms by minimizing MPSD function for $\mathrm{Cu}(\mathrm{II})$ onto kaolinite
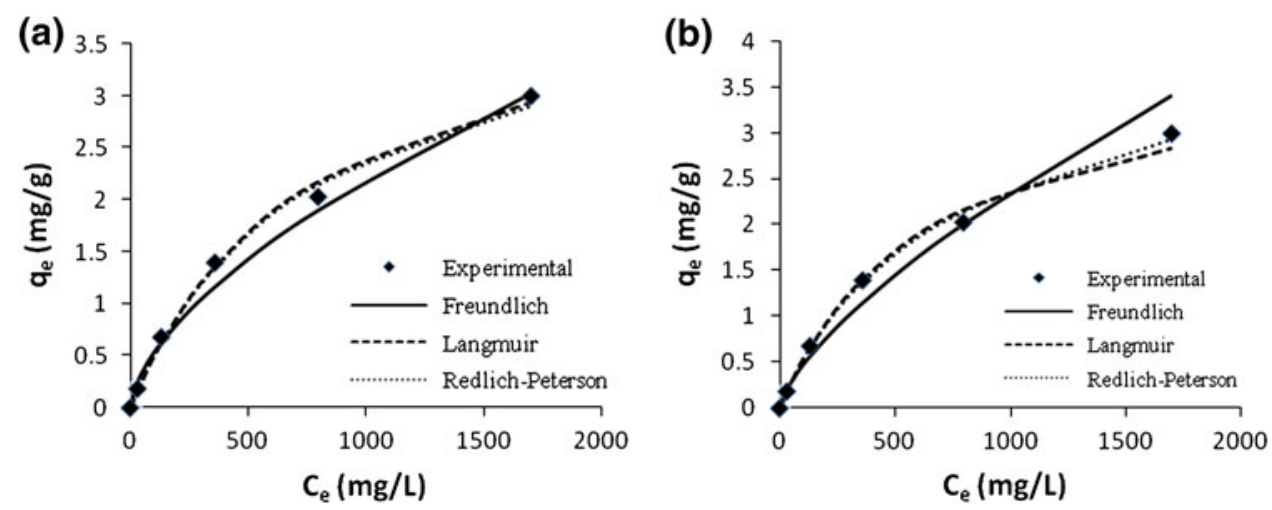
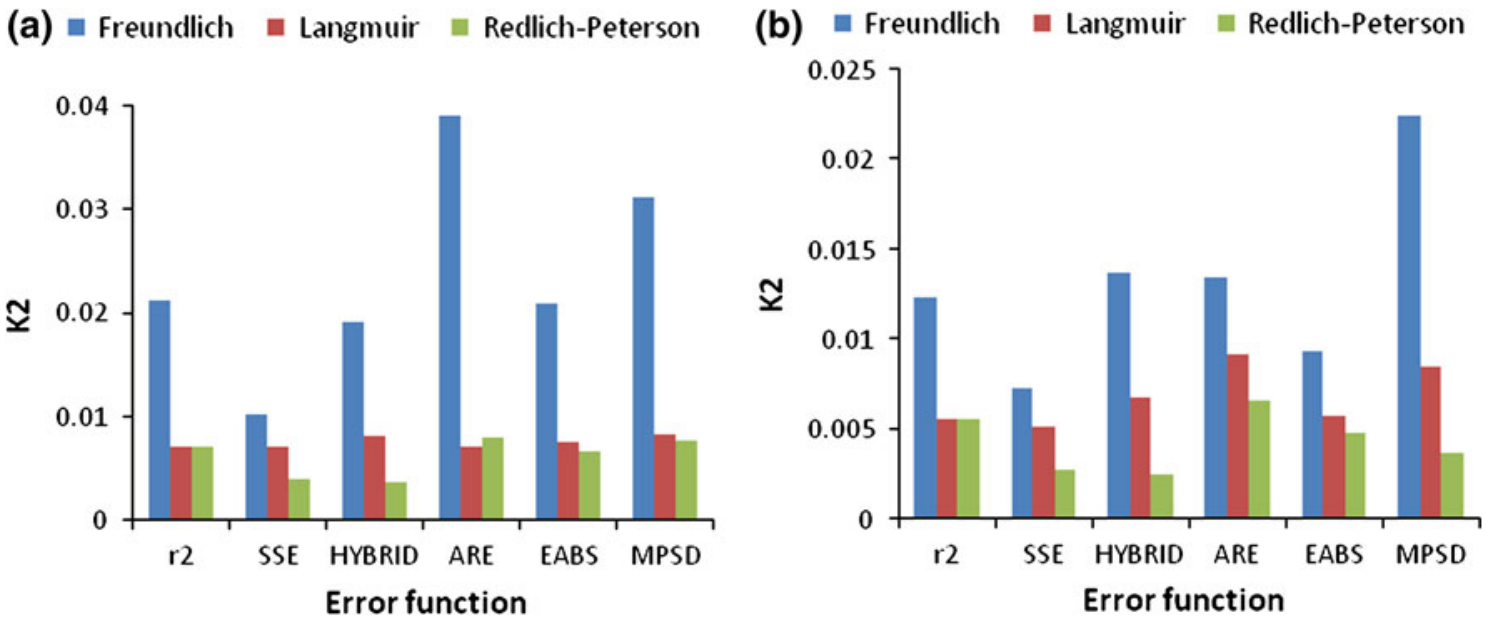

Fig. 8 Coefficient of non-determination for isotherms of $\mathbf{a} \mathrm{Zn}(\mathrm{II}), \mathbf{b} \mathrm{Cu}(\mathrm{II})$ onto kaolinite

the transformed experimental data and the predicted isotherms (Kumar et al. 2008). Figure 8a, b shows the calculated $K^{2}$ values for the isotherms predicted by minimizing or maximizing the various error functions for $\mathrm{Zn}$ (II) and $\mathrm{Cu}$ (II) onto kaolinite, respectively. From Fig. 8a, b, it is observed that SSE function least unexplain the two-parameter isotherm, suggesting this function as the best function to minimize the error distribution between the experimental and predicted twoparameter isotherms, namely the Freundlich and Langmuir isotherms. Thus, for the studied system, SSE was found to be the best error function to be used in predicting the optimum isotherm if the objective is to select the best-fit isotherm out of two-parameter isotherms. In the case of three-parameter Redlich-Peterson isotherm, it can be observed that HYBRID was found to be the best error function in minimizing the error distribution between the experimental equilibrium data and the predicted isotherms (Fig. 8a, b). Thus, the results of HYBRID can be useful in predicting the optimum isotherm based on the threeparameter Redlich-Peterson isotherm.

\section{Conclusion}

A comparison of linear and non-linear regression methods in selecting the optimum isotherm was made to the experimental equilibrium data of $\mathrm{Zn}$ (II) and $\mathrm{Cu}(\mathrm{II})$ sorption by kaolinite. The coefficient of determination $\left(r^{2}\right)$ was used to select the best-fit linear theoretical isotherm. In the case of non-linear regression method, six error functions were used to predict the parameters involved in the two- and three-parameter isotherms and also to predict the optimum isotherm. The examination of all these error estimation methods showed that the Langmuir model provides the best fit for the experimental equilibrium data (i.e. highest $r^{2}$ and lowest SSE, HYBRID, ARE, EABS, and MPSD values). For two-parameter isotherms, a SSE function and for threeparameter isotherms, a HYBRID function were found to be a better option to minimize the error distribution between the experimental and predicted isotherms. The coefficient of non-determination was found to be more useful statistical term in identifying the best error function while selecting the optimum isotherm. 
Acknowledgments Authors are thankful to the Editor-in-Chief J. Nouri and anonymous reviewers for their constructive comments which greatly improve the quality of the manuscript.

\section{References}

Abdel-Ghani NT, Hegazy AK, El-Chaghaby GA (2009) Typha domingensis leaf powder for decontamination of aluminium, iron, zinc and lead: biosorption kinetics and equilibrium modeling. Int J Environ Sci Technol 6(2):243-248

Allen SJ, Gan Q, Matthews R, Johnson PA (2003) Comparison of optimized isotherm models for basic dye adsorption by kudzu. Bioresour Technol 88(2):143-152

Ayoub GM, Semerjian L, Acra A, El-Fadel M, Koopman B (2001) Heavy metal removal by coagulation with seawater liquid bittern. J Environ Eng 127(3):196-202

Bhattacharya AK, Mandal SN, Das SK (2006) Adsorption of Zn(II) from aqueous solution by using different adsorbents. Chem Eng J 123(1-2):43-51

Bose P, Bose MA, Kumar S (2002) Critical evaluation of treatment strategies involving adsorption and chelation for wastewater containing copper, zinc, and cyanide. Adv Environ Res 7(1):179-195

Eckenfelder WW (2000) Industrial water pollution control. McGrawHill, New York, pp 451-457

Ho YS (2004) Selection of optimum sorption isotherm. Carbon 42(10):2115-2117

Ho YS, Porter JF, McKay G (2002) Equilibrium isotherm studies for the sorption of divalent metal ions onto peat: copper, nickel and lead single component systems. Water Air Soil Pollut 141(1-4):1-33

Ho YS, Chiu WT, Wang CC (2005) Regression analysis for the sorption isotherms of basic dyes on sugarcane dust. Bioresour Technol 96(11):1285-1291

Jokela P, Keskitalo P (1999) Plywood mill water system closure by dissolved air flotation treatment. Water Sci Technol 40(11-12):33-42

Jüttner K, Galla U, Schmieder H (2000) Electrochemical approaches to environmental problems in the process industry. Electrochim Acta 45(15-16):2575-2594

Kumar KV (2006) Comparative analysis of linear and non-linear method of estimating the sorption isotherm parameters for malachite green onto activated carbon. J Hazard Mater 136(2):197-202

Kumar KV, Sivanesan S (2006) Isotherm parameters for basic dyes onto activated carbon: comparison of linear and non-linear method. J Hazard Mater 129(1-3):147-150

Kumar KV, Sivanesan S (2007) Sorption isotherm for safranin onto rice husk: comparison of linear and non-linear methods. Dyes Pigments 72(1):130-133
Kumar KV, Porkodi K, Rocha F (2008) Isotherms and thermodynamics by linear and non-linear regression analysis for the sorption of methylene blue onto activated carbon: comparison of various error functions. J Hazard Mater 151(2-3):794-804

Kunda S, Gupta AK (2006) Arsenic adsorption onto iron oxide-coated cement (IOCC): regression analysis of equilibrium data with several isotherm models and their optimization. Chem Eng J 122(1-2):93-106

Malek A, Farooq S (1996) Comparison of isotherm models for hydrocarbon adsorption on activated carbon. AIChE J 42(11): 3191-3201

Matis KA, Zouboulis AI, Lazaridis NK, Hancock IC (2003) Sorptive flotation for metal ions recovery. Int $\mathrm{J}$ Miner Process 70(1-4):99-108

Ng JCY, Cheung WH, McKay G (2002) Equilibrium studies of the sorption of $\mathrm{Cu}(\mathrm{II})$ ions onto chitosan. J Colloid Interface Sci 255(1):64-74

Ng JCY, Cheung WH, McKay G (2003) Equilibrium studies for the sorption of lead from effluents using chitosan. Chemosphere 52(6): 1021-1030

Porter JF, McKay G, Choy KH (1999) The prediction of sorption from a binary mixture of acidic dyes using single- and mixedisotherm variants of the ideal adsorbed solute theory. Chem Eng Sci 54(24):5863-5885

Semerjian L, Ayoub GM (2003) High-pH-magnesium coagulationflocculationin wastewater treatment. Adv Environ Res 7(2):389-403

Shahmohammadi-Kalalagh Sh, Babazadeh H, Nazemi AH, Manshouri $\mathrm{M}$ (2011) Isotherm and kinetic studies on adsorption of $\mathrm{Pb}$, $\mathrm{Zn}$ and $\mathrm{Cu}$ by kaolinite. Caspian J Environ Sci 9(2):243-255

Sposito G (1989) The chemistry of soils. Oxford University Press, New York

Subramanyam B, Das A (2009) Linearized and non-linearized isotherm models comparative study on adsorption of aqueous phenol solution in soil. Int J Environ Sci Technol 6(4):633-640

Tashauoei HR, Movahedian Attar H, Amin MM, Kamali M, Nikaeen M, Vahid Dastjerdi M (2010) Removal of cadmium and humic acid from aqueous solutions using surface modified nanozeolite A. Int J Environ Sci Technol 7(3):497-508

Vimonses V, Lei SH, Jin B, Chow WK, Saint CH (2009) Kinetic study and equilibrium isotherm analysis of congo red adsorption by clay materials. Chem Eng J 148(2-3):354-364

Wingenfelder U, Hansen C, Furrer G, Schulin R (2005) Removal of heavy metals from mine water by natural zeolites. Environ Sci Technol 39(2):4606-4613

Wong YC, Szeto YS, Cheung WH, McKay G (2004) Adsorption of acid dyes on chitosan equilibrium isotherm analyses. Process Biochem 39(6):695-704

Yong RN, Mohamed AMO, Warketin BP (1992) Principles of contaminants transport in soil. Elsevier, Amsterdam

Zavvar Mousavi H, Seyedi SR (2011) Nettle ash as a low cost adsorbent for the removal of nickel and cadmium from wastewater. Int J Environ Sci Technol 8(1):195-202 